\title{
Staff's and family members' spiritual well-being in relation to help for residents with dementia
}

\author{
John Fisher \\ Faculty of Medicine, Dentistry \& Health Sciences, University of Melbourne, Australia \\ Correspondence: J ohn W Fisher. Gandarra Palliative Care Unit, Ballarat Health Services, PO Box 199 Ballarat, Vic 3353 \\ Australia. Telephone: 61-438-395-915. Email: jwfisher@unimelb.edu.au
}

Received: December 29, 2011

Accepted: February 14, 2012

Published: November 1, 2012

DOI : $10.5430 /$ jnep.v2n4p77

URL: http://dx.doi.org/10.5430/jnep.v2n4p77

\section{Abstract}

Background: Spiritual well-being of providers and patients is paramount for holistic care in nursing. Spiritual well-being is reflected in relationships in four areas, namely with self, others, environment and/or Transcendent Other.

Method: Fisher's 20-item Spiritual Health and Life-Orientation Measure (SHALOM) was used to assess these four key components of spiritual health. A survey was completed by staff and family members of residents in a dementia care unit, to record three responses on SHALOM, namely their ideals for spiritual health, their lived experiences, and what they thought residents need for spiritual nurture in these four areas. Demographic variables were investigated, with respect to any impact on respondents' spiritual well-being.

Results: Variations were found in the staff's and family members' spiritual well-being based on age, religious group membership and activities, and whether or not the respondent was facing a spiritual challenge. However, regression analyses showed that these variables had no significant influence on the help that staff thought residents need to nurture their spiritual well-being. Regression analyses did show that staff's ideals contributed greatest explanation of variance in terms of help staff believe is needed for spiritual nurture of residents. On the other hand, it was the lived experiences of family members that showed greatest influence on what help they thought residents needed. This was especially true for family members who had difficulty living up to their own ideals. Even though they based their judgements on different rationale, staff and family members agreed on the priorities to be set in nurturing residents' spiritual well-being in a dementia care unit.

Conclusion: Congruence was found between staff's and family members' perceptions of help needed to nurture residents' spiritual well-being. This study, using the spiritual well-being questionnaire called SHALOM, revealed that staff acted professionally basing their judgment on ideals, whereas family members reflected their own lived experience, when determining what they thought was needed to help nurture residents' spiritual well-being.

\section{Key words}

Spiritual well-being, Dementia, Residential care, Nurses, Family

\section{Introduction}

Considerable interest is currently being shown in society about the spiritual well-being of people ${ }^{[1,2]}$. 'At least since Nightingale, spirituality has been central to the essence of modern nursing ${ }^{[3]}$. Nurses have historically embraced a holistic 
approach to care for patients ${ }^{[4]}$. Increasing numbers of publications of holistic nursing journals, books and research and position papers focusing on the spiritual well-being (SWB) of patients show the growing interest and concern in this area $^{[5-13]}$.

There are nearly as many definitions of spirituality as there are people who attempt to describe it. The following description of spiritual health will be used in this paper.

Spiritual health is a fundamental dimension of people's overall health and well-being, permeating and integrating all the other dimensions of health (i.e. the physical, mental, emotional, social and vocational).

Spiritual health is a dynamic state of being, shown by the extent to which people live in harmony within relationships in up to four domains of spiritual well-being, namely with themselves, with others, with the environment and/or with a Transcendent other, commonly called God ${ }^{[14]}$.

'Spiritual care is integral to quality nursing for nursing home residents' ${ }^{[15]}$. The process for accreditation of aged care services in Australia involves investigation of the 'Cultural and spiritual life' of residents ${ }^{[16]}$. Residents in a dementia care unit are often unable to express their own views cogently. This study was undertaken in order to check consistency of spiritual care expressed by family members, who had been caring for patients at home, with that of staff, who are now caring for them as residents, in a dementia care unit in regional Victoria, Australia.

Fisher's Spiritual Health And Life-Orientation Measure (SHALOM) was designed to identify respondents' perceptions of the importance of four key factors for spiritual health described above ${ }^{[17]}$. SHALOM was initially developed with secondary school students, in the belief that the language so employed would also make the instrument suitable for use with adults ${ }^{[18]}$. Extensive psychometric testing of this instrument with participants in educational and health services and the general community has shown its validity and reliability across various settings and age groups. Exploratory and confirmatory factor analyses, and item response theory analysis, have confirmed the distribution of the 20 items into four coherent factors in SHALOM, supporting the theoretical foundation upon which it was based ${ }^{[19-21]}$.

\section{Aims of this study}

The basic instrument SHALOM sought two responses to indicate: (1) staff's and family members' ideals for SWB as well as (2) their lived experience. Comparing these two provides a measure of spiritual harmony or dissonance in each of four domains of SWB. A third assessment was also made using SHALOM, in that participants were asked to indicate what (3) they think is needed to nurture spiritual well-being of residents in a dementia care unit.

It is the quality of relationships that people have with themselves, with others, nature and/or God that reflect their spiritual well-being. These four domains are investigated using SHALOM.

Previous studies using SHALOM have shown that carers' own spiritual well-being influenced their perceptions of the help they provide to clients for the clients' SWB ${ }^{[22]}$. So, staff's and family members' ideals and lived experiences of SWB were investigated to see how these influenced what they thought was needed to nurture residents' SWB. Demographic factors were also investigated for their potential impact on staff's and family members' SWB.

\section{Subjects and method}

\subsection{Study design}

A questionnaire survey method was used to investigate spiritual well-being in a dementia care unit. Following ethics approvals at university and hospital level, the SHALOM questionnaire was administered to staff and family members of a 30-bed residential dementia care unit, in regional Victoria, Australia. 


\subsection{Power analysis}

Even though the sample was small, post hoc power analysis using $\mathrm{G}^{*}$ Power 3 yielded a value of $0.51^{[23]}$. As this value was less than 0.8 , the statistically significant differences, that were found between staff and family members, indicate real differences exist between the groups.

\subsection{Experimental method}

In order to provide as little disruption as possible to normal activities in the dementia care unit, whilst optimising opportunities for participation by staff and family members, questionnaires were given to respondents in small groups, at a staff meeting and a regular scheduled meeting of family members. Individuals were followed up by the coordinator of the unit if they were unable to be present when the groups met. Participation in the project was voluntary. All staff participated and $73 \%$ of the residents had one of their family members complete the survey. Some residents have no regular family contact and others were not available at the time of the study. However, everyone who was invited willingly participated.

\subsection{Research instrument}

A two-page printed questionnaire was given to staff and family members of patients. The front page sought demographic data, such as gender (F or M), age (assessed by decade, as previous studies have revealed reticence by some Australian respondents to give exact age), staff position (Division 1 or 2 Nurse, or Domestic carer). Although nature of relationship of family member to resident was not asked, observation revealed that it was mainly a spouse who completed the survey. As there is considerable discussion in the literature about the nexus between spirituality and religion, it is standard practice by this researcher to include questions which interrogate this connection. To this end, participation in religious activities was selected from 'not at all, less than once a month, once a month, once in 2-4 weeks, once a week'. Participants were asked if they had a religious group with which they were affiliated and whether or not they were experiencing a spiritual challenge, both answered using a Yes/No response. Spiritual challenge was not specified, but left to the participants for their interpretation.

Page two of the survey presented SHALOM, a 20-item instrument, with five items to assess each of four domains of spiritual well-being. The Personal domain comprises the items 'meaning, inner peace, identity, joy and self-awareness'. The Communal domain comprises 'love others, trust, kindness, respect others, forgiveness'. The Environmental domain comprises 'harmony with environment, connect with nature, "magic" in the environment, one with nature, awe at view'. The Transcendental/God domain comprises 'oneness with God, relation with Divine, worship Creator, prayer, and peace with God'.

Participants were asked to provide three responses on each of these 20 items, using a five-point Likert scale from very high (5) to very low (1), to show:

1) how important you think each area is for an ideal state of spiritual well-being

2) how you feel each item reflects your personal experience most of the time

3) what help you think dementia patients need to nurture their spiritual well-being, ${ }^{[24]}$.

Scale scores were calculated by taking the mean value for each set of five items in the four domains of SWB.

\subsection{Statistical analyses}

SPSS for Windows version 19 was used to calculate means (SD) for ideals, lived experiences and helps for the 20 items and the four factors of SHALOM, whose validity was revealed using Principal Components Analysis. Matched pairs and independent t-tests were also calculated to investigate relationships between the three categories of SHALOM (namely, 
ideals, lived experiences and helps). Linear regression analyses were employed to investigate influences on levels of help for residents' SWB.

\section{Results}

\subsection{Participant details}

Table 1 shows participants in the study. Staff were identified by position and both groups were listed by age. As most family members were spouses, it is not surprising that they were older than staff (see Table 1).

Table 1. Details of participants

\begin{tabular}{|c|c|c|c|c|c|c|c|}
\hline & & \multirow{2}{*}{$\mathbf{N}$} & \multicolumn{5}{|c|}{ Age } \\
\hline & & & $20 \mathrm{~s}$ & $30 s$ & $40 \mathrm{~s}$ & $50 \mathrm{~s}$ & $60+$ \\
\hline \multirow{3}{*}{$\begin{array}{l}\text { Family } \\
\text { members }\end{array}$} & male & 10 & 1 & & 2 & 3 & 4 \\
\hline & female & $13^{*}$ & & 1 & 2 & 3 & 6 \\
\hline & Total & 23 & \multicolumn{5}{|c|}{$* 1$ age not given } \\
\hline \multirow{4}{*}{ Staff } & Div.1 & 7 & & 1 & 2 & 4 & \\
\hline & Div.2 & 10 & 2 & $4 \#$ & 2 & 2 & \\
\hline & Domcare & 4 & & 1 & 2 & 1 & \\
\hline & Total & 21 & \multicolumn{5}{|c|}{$\#=1$ male; other 20 are female } \\
\hline
\end{tabular}

Note. NB Div 1 = Registered Nurse; Div 2 = Enrolled Nurse; Domcare = Domestic Care

\subsection{Suitability of the SHALOM instrument}

When assessing the suitability of data for factor analysis, the Kaiser-Meyer-Olkin (KMO) measure of sampling adequacy should yield a value of at least 0.6 (on a scale that ranges from 0 to 1 ) for a good factor analysis ${ }^{[25]}$. The 20 -item SHALOM instrument was shown to comprise four unique factors, each with five items as described above. Principal components analysis extracted a single factor for each group of five items, testing ideals, lived experiences and helps for SWB. All KMO values in this study exceeded 0.6 , with most of the variance explained exceeding $60 \%$, indicating the reliability of the scales (see Table 2).

Table 2. Principal component analysis for four domains of SHALOM, in three categories

\begin{tabular}{|c|c|c|c|c|c|c|c|c|}
\hline \multirow[b]{3}{*}{ category } & \multicolumn{8}{|c|}{ Domains of SWB in SHALOM } \\
\hline & Per & & Com & & Env & & Tra & \\
\hline & KMO & $\%$ & KMO & $\%$ & KMO & $\%$ & $\mathrm{KMO}$ & $\%$ \\
\hline ideal & .71 & 72.9 & .61 & 66.5 & .81 & 65.3 & .85 & 71.8 \\
\hline $\exp$ & .83 & 69.6 & .62 & 53.9 & .73 & 62.1 & .88 & 80.4 \\
\hline help & .86 & 68.9 & .83 & 66.3 & .81 & 69.9 & .85 & 79.7 \\
\hline
\end{tabular}

Note. NB Per $=$ Personal, Com $=$ Communal, Env $=$ Environmental, Tra $=$ Transcendental domains of SWB. Exp $=$ lived experience, help $=$ perceived help for dementia patients

\subsection{Levels of spiritual well-being for staff and family members}

The staff and family members gave positive responses, in that their stated ideals, lived experiences and help needed for residents' SWB were reported to be above the middle value in the range of possible scores (i.e., score of 3 on the scale from 1-5) in each of the four domains of spiritual well-being (see Table 3). These results indicate good levels of SWB among staff and family, with satisfying relationships with self, with others, nature and God. 
They also expressed consistently high expectations for care of the residents' SWB.

Table 3. Mean (SD) values for four Domains of SWB in three categories using SHALOM

\begin{tabular}{llllllll}
\hline & \multicolumn{2}{l}{ Staff -category } & & & \multicolumn{2}{l}{ Family members - category } \\
\cline { 2 - 4 } $\begin{array}{l}\text { Domain of SWB } \\
\text { (in SHALOM) }\end{array}$ & ideal & lived exp & $\begin{array}{l}\text { help } \\
\text { needed }\end{array}$ & & ideal & lived exp & help needed \\
\hline Personal & $4.39(.55)$ & $4.51(.60)$ & $4.12(.60)$ & & $4.27(.75)$ & $3.69(.77)$ & $3.76(.82)$ \\
Communal & $4.55(.50)$ & $4.60(.52)$ & $4.18(.56)$ & & $4.47(.72)$ & $4.25(.66)$ & $3.85(.87)$ \\
Environmental & $3.86(.85)$ & $4.01(.86)$ & $3.69(.83)$ & & $3.80(1.10)$ & $3.64(.95)$ & $3.46(1.14)$ \\
Transcendental & $3.82(1.14)$ & $3.44(1.21)$ & $3.85(.90)$ & & $3.96(.72)$ & $3.62(.89)$ & $3.55(.85)$ \\
\hline
\end{tabular}

With the staff's very positive scores it was not surprising to find that their lived experiences scored significantly higher than the corresponding family members' for the Personal $(t(42)=-3.96, p<.001)$ and Communal $(t(42)=-2.36, p<.05)$ domains. Staff were coming from a very positive position of spiritual health in these areas, which has previously been shown to relate to quality of help provided to patients for their spiritual well-being ${ }^{[22]}$.

\subsection{Factors affecting participants' spiritual well-being and their influ- ence on help for residents}

\subsubsection{Staff position}

No significant differences were found between the occupational groups comprising the staff, namely Division One (with general nursing qualification) and Division Two (with enrolled nursing qualification) nurses and Domestic Care staff.

As there was only one male staff member, testing by gender was inappropriate.

\subsubsection{Age}

The age of 50 years was chosen to divide the staff and family members into two groups of reasonably equal size to enable adequate statistical testing in this small sample.

* Staff - The under 50s scored significantly higher than the over 50 s on the lived experience item inner peace $(t(19)=2.39$, $p<.05$ ), expressing greater well-being in the Personal domain. The over 50s were more idealistic in the Personal domain with higher scores than the under 50 s for identity $(t(19)=-3.83, p<.05)$ and self-awareness $(t(19)=-2.17, p<.05)$. They also had more idealistic expectations regarding harmony with the environment $(t(19)=-2.76, p<.05)$. The over 50 s showed considerably higher ideals and lived experience on the Transcendental domain/God factor. These results suggest that reflection and contemplation could be significant means by which older staff enhance their spiritual well-being. The most important finding is that no differences by age were observed for staff's expression of help-needed-for-residents with dementia despite the personal variations amongst staff.

* Family members - As previously stated, the family members were significantly older than the staff. The over 50 s had higher scores than the under 50s in the Personal $(t(20)=2.29, p<.05)$ and Environmental $(t(20)=3.19, p<.01)$ domains.

Family members did not show the same variation by age on the Transcendental domain/God factor as was shown amongst staff, nor did the under 50s reflect similar positive personal attitudes that were shown among staff. Once again, age of family members did not significantly influence levels of help needed for residents' SWB.

\subsubsection{Religious group}

Amongst staff, 13 were affiliated with religious groups, eight were not. Amongst family members 20 were affiliated with religious groups, two were not. The very small number of non-affiliates could skew comparisons, so the staff and family members were considered together, as a single entity. 
As would be expected, expressions of lived experience in relation to God were significantly higher for those members who were affiliated with a religious group $(t(41)=2.34, p<.05)$. However, there was no difference in expectations of help for residents' SWB, based on participants' religious affiliation $(t(41)=-.42, p=.68 \mathrm{~ns})$.

\subsubsection{Religious activities}

It was not surprising to find that the regular church-attenders had higher expectations and experience of worship enhancing their spiritual well-being (ideal $t(29)=2.45, p<.05$, experience $t(29)=2.12, p<.05$ ). They also experienced the positive effect of prayer on their spiritual well-being $(t(29)=2.23, p<.05)$. The less frequent church-attenders had a more idealistic expectation that being one with nature would nurture their spiritual well-being $(t(27)=-2.12, p<.05)$. However, no significant variation was found on help for residents' SWB, based on religious activities of staff and family members.

\subsubsection{Spiritual challenge}

The six staff and five family members who acknowledged facing a spiritual challenge were more idealistic than the others in the Personal, Environmental and Transcendental/ God-factors. These people were sensitive to spiritual challenges but did not display significantly different results in their lived experiences nor in perceptions of help needed for residents' SWB.

\section{Discussion}

\subsection{Determining residents' needs for spiritual well-being}

All staff and family members perceived residents' need for support for SWB similarly. There was no differentiation by age, gender, etc according to demographic data collected in this study.

A previous study using SHALOM with nurses showed that they projected their lived experience onto the way they saw clients having their spiritual well-being nurtured ${ }^{[22]}$. Therefore linear regression analyses, using ideals and lived experiences as predictor variables, were performed on perceived needs for residents' SWB by both staff and family members in this study (see Table 4).

Table 4. Linear regression analyses of perceived help for residents' SWB

\begin{tabular}{lllllllll}
\hline & \multicolumn{7}{c}{ Domains of SWB in SHALOM } \\
\cline { 2 - 9 } & Staff & \multicolumn{7}{c}{ Family members } \\
\hline RA & Per & Com & Env & Tra & Per & Com & Env & Tra \\
$\mathrm{F}$ & $9.5^{* *}$ & $10.3^{* *}$ & $10.8^{* *}$ & $8.0^{* *}$ & 2.6 & $3.9^{*}$ & $6.6^{* *}$ & 1.9 \\
$\mathrm{R}^{2}$ & .51 & .53 & .55 & .47 & .21 & .28 & .40 & .16 \\
$\beta$ Bideal & .71 & .94 & .65 & .79 & .24 & -.07 & .30 & .06 \\
Bexp & -.05 & -.41 & .16 & -.16 & .36 & .57 & .39 & .36 \\
\hline
\end{tabular}

NB ${ }^{*} p<.05 ; * * p<.01, \exp =$ lived experience

These results reveal that the staff's ideals provided greater explanation of variance in their perceptions of help for residents' SWB, much more than staff's lived experiences did. This finding contrasted with the level of help perceived to be provided for clients by nursing staff, which showed the reverse order, in the previous study reported above ${ }^{[22]}$. The staff in this residential care unit acted in a very professional manner, by putting aside their own lived experience, relying on ideals for determining perceived needs for help with residents' SWB. In contrast, the results show that family members projected their lived experiences onto their perception of residents' need for help with SWB. 


\subsection{Priorities for developing spiritual well-being}

Although they used different rationale to determine what help they thought residents need for nurturing their SWB, staff and family members in this study showed remarkably similar rank order of priorities. An inspection of the top ten items reveals that nine are the same, although the order differs slightly (see Table 5).

Table 5. Top ten items perceived to be important for help with residents'sWB

\begin{tabular}{lll}
\hline Rank order & Staff's perceptions & Family members' perceptions \\
\hline 1 & love others & love others \\
2 & trust & Trust \\
3 & joy\# & Identity \\
4 & identity & respect others* \\
5 & inner peace & inner peace \\
6 & kindness* & peace with God \\
7 & peace with God & joy\# \\
8 & self-awareness & self-awareness \\
9 & oneness with God & oneness with God \\
10 & meaning in life & meaning in life \\
\hline
\end{tabular}

NB $*=$ not in the other group's top items. \#= different order

Developing relationships in the Communal domain of spiritual well-being were of greatest concern to the staff and family members, closely followed by those in the Personal domain. However, both the staff and family members perceived that the Transcendental/God factor was of greater importance than the Environmental factor for the residents to develop spiritual well-being.

\section{I mplication for nursing practice}

Further study is warranted to clarify the relationship between nurses' perceptions of patients' needs for help, and nurses' perceived level of help they provide. These could also be compared with patients' reports on level of help they receive for spiritual well-being, if they were competent to make such an assessment (i.e., not dementia patients).

It is proposed that SHALOM could be beneficial to aged care services seeking a tool to help staff reflect on their own spiritual well-being as well as the spiritual life of their residents. This would be in keeping with accreditation requirements, which require spiritual needs of patients to be considered as part of holistic care ${ }^{[15]}$.

\section{Strengths and weaknesses of this study}

This study provided positive outcomes related to nursing practice in an exploration of patients' spiritual needs in a residential dementia care unit. The sample was small in size, yet it comprised all the staff and vast majority of families representing residents in this unit. Despite the size, significant results were obtained providing further evidence for the sensitivity of SHALOM as an investigative instrument.

\section{Conclusion}

This study has shown that SHALOM can be a useful tool to help nursing staff and others reflect on their own spiritual well-being and see how well their own views match with others', as well as patients' needs for help. Responses on three categories of SHALOM provided assessments for the Personal, Communal, Environmental, and Transcendental/God domains of spiritual well-being in terms of staff's and family's (1) ideals; (2) lived experience; and (3) what help they thought residents with dementia need to nurture their SWB. 
Although variations were found in the staff's and family members' own spiritual well-being based on age, religious group membership and activities, and whether or not the participant was facing a spiritual challenge, these variables had no significant impact on what staff and family members thought was needed to help nurture residents' spiritual well-being.

The staff in this study were able to differentiate between their ideals and lived experiences when it came to deciding what they thought would be best for nurturing residents' spiritual well-being. The staff's ideals contributed greatest variance in explaining what help they thought residents needed to nurture their SWB. The family members, on the other hand, used their lived experience as a basis for selecting what they considered most appropriate for nurturing the spiritual well-being of residents with dementia. Even though they used different rationale, the staff and family members agreed on the priorities they thought should be set in meeting the residents' needs for nurturance of their spiritual well-being.

\section{Acknowledgements}

Sincere thanks are expressed for the generous manner in which the staff and family members associated with this residential care unit participated in the study. Because of their support, it is hoped that these results will enable and encourage others to share mutual concerns for the spiritual well-being of similar residents with dementia.

\section{References}

[1] Harding SR, Flannelly KJ, Galek K, Tannenbaum HP. Spiritual care, pastoral care, and chaplains: Trends in the health care literature. J Health Care Chapl. 2008; 14: 99-117. PMid:18697354 http://dx.doi.org/10.1080/08854720802129067

[2] Gilbert P. Seeking inspiration: The rediscovery of the spiritual dimension in health \& social care in England. Ment Health, Relig \& Cult. 2010; 13: 533-546. http://dx.doi.org/10.1080/13674676.2010.488422

[3] Wright KB. Professional, ethical, and legal implications for spiritual care in nursing. Image: J Nurs Schol. $1998 ; 30: 81-83$. http://dx.doi.org/10.1111/j.1547-5069.1998.tb01241.x

[4] Ronaldson S(ed.). Spirituality: The heart of nursing. Melbourne: Ausmed Pub., 1997.

[5] McSherry W. Nurses' perceptions of spirituality and spiritual care. Nurs Standard. 1998; 13: 36-40.

[6] Sherwood GD. The power of the nurse-client encounter: Interpreting spiritual themes. J Holist Nurs. 2000; 18:159-175. PMid:11847768 http://dx.doi.org/10.1177/089801010001800207

[7] MacKinlay E. Spiritual care: Recognising spiritual needs of older adults. J Relig, Spir \& Aging. 2006; $18:$ 59-71. http://dx.doi.org/10.1300/J496v18n02_05

[8] Moberg DO. Disabilities, spirituality \& well-being in late life: Research foundations for study \& practice. J Relig, Spir \& Aging. 2008; 20: 313-340. http://dx.doi.org/10.1080/15528030802232379

[9] Goodall MA.The evaluation of spiritual care in a dementia care setting. Dementia. 2009; 8: 167-183. http://dx.doi.org/10.1177/1471301209103249

[10] Bursell J, Mayers CA. Spirituality within dementia care: perceptions of health professionals. Br J Occup Ther. 2009 ; 73: $144-151$. http://dx.doi.org/10.4276/030802210X12706313443866

[11] Jolley D, Benbow SM, Grizzell M, Willmott S, Bawn S, Kingston P. Spirituality and faith in dementia. Dementia. 2010; 9: 311-325. http://dx.doi.org/10.1177/1471301210370645

[12] Keast K, Leskovar C, Brohm R. A systematic review of spirituality and dementia in LTC. Ann Long Term Care. 2010 ; $18: 41-47$.

[13] MacKinlay E, Trevitt C. Living in Aged Care: Using spiritual reminiscence to enhance meaning in life for those with dementia. Int J Ment Health Nurs. 2010; 19: 394-401. PMid:21054725 http://dx.doi.org/10.1111/j.1447-0349.2010.00684.x

[14] Fisher JW. Helps to fostering students' spiritual health. Int J Children's Spir. 1999; 4: 29-49. http://dx.doi.org/10.1080/1364436990040104

[15] Hicks TJ. Spirituality and the elderly: nursing implications with nursing home residents. Geriat Nurs. 1999; 20 : 144-146. http://dx.doi.org/10.1016/S0197-4572(99)70006-6

[16] Department of Health \& Family Services. Standards \& Guidelines Manual. Kingston, ACT: CanPrint Communications P/L, 1998.

[17] Fisher JW. Developing a spiritual health and life-orientation measure for secondary school students. In Proceedings of the University of Ballarat Annual Research Conference, 15 October, 1999; Ballarat. Edited by Wittwer V, Baird P. Ballarat: UB Research \& Graduate Studies Office. 1999; 57-63.

[18] Fisher J. Development and application of a spiritual well-being questionnaire called SHALOM. Religions. $2010 ; 1$ : $105-121$. http://dx.doi.org/10.3390/rel1010105 
[19] Gomez R, Fisher JW. Domains of spiritual well-being and development and validation of the Spiritual Well-Being Questionnaire. Pers and Indiv Diff. 2003; 35: 1975-1991. http://dx.doi.org/10.1016/S0191-8869(03)00045-X

[20] Gomez R, Fisher JW. Item Response Theory analysis of the Spiritual Well-Being Questionnaire. Pers and Indiv Diff. 2005; 38: 1107-1121. http://dx.doi.org/10.1016/j.paid.2004.07.009

[21] Gomez R, Fisher JW. The Spiritual Well-Being Questionnaire: Testing for model applicability, measurement and structural equivalencies and latent mean differences across gender. Pers and Indiv Diff. 2005; 39: 1383-1393. http://dx.doi.org/10.1016/j.paid.2005.03.023

[22] Fisher JW, Brumley DJ. Nurses' and carers' spiritual well-being in the workplace. Australian J Adv Nurs. 2008 ; 25 : $49-57$.

[23] Faul F, Erdfelder E, Buchner A, Lang A-G. G*Power 3: A flexible statistical power analysis program for the social, behavioural, and biomedical sciences. Behav Res Methods. 2007; 39: 175-191. PMid:17695343 http://dx.doi.org/10.3758/BF03193146

[24] Fisher JW. Reaching the Heart: Assessing and nurturing spiritual well-being via education [Inernet]. EdD dissertation, University of Ballarat, Australia, 2009. Available from: http://archimedes.ballarat.edu.au:8080/vital/access/HandleResolver/1959.17/13481

[25] Tabachnick BG, Fidell LS. Using multivariate statistics (5th Ed.). Boston: Pearson Education, 2007. 